\title{
Asymmetric membrane filters for the removal of leukocytes from blood
}

\author{
A. Bruil, W.G. van Aken, T. Beugeling, and J. Feijen* \\ Department of Chemical Technology, Section of Biomaterials, University of Twente, Enschede, \\ The Netherlands

\section{Steneker} \\ Department of Histology, Medical Faculty, Free University, Amsterdam, The Netherlands
}

\section{J.G. Huisman and H. K. Prins}

Central Laboratory of the Netherlands Red Cross Blood Transfusion Service, Amsterdam, The Netherlands

As part of a study on the mechanisms of leukocy te filtration, the influence of pore size distribution on filter efficiency was investigated. Conventional leukocyte filters are not suitable for model studies, as these filters are composed of tightly packed synthetic fibers, with a poorly defined porous structure. Therefore, open cellular polyurethane membranes with pore size distributions varying from approximately 15 to $65 \mu \mathrm{m}$ were prepared. Filtration experiments with stacked packages of these membranes showed that leukocytes are best removed ( $>99 \%)$ by filters with a pore size distribution of 11-19 $\mu \mathrm{m}$. These pore sizes approach the size of leukocytes $(6-12 \mu \mathrm{m})$. However, due to fast clogging, blood flow through these filters is rapidly reduced, which results in a low filter capacity. With an asymmetric membrane filter, in which the pore size decreases from about 65 to $15 \mu \mathrm{m}$ in the direction of blood flow, both moderate removal of leukocytes $(>80 \%)$ and maintenance of flow $(-0.2 \mathrm{~mL} / \mathrm{s})$ are obtained. This results in efficient leukocyte removal. From cell analysis of both filtrate and filter, it is concluded that adhesion rather than sieving is the major filtration mechanism. Thus, further optimization of the filter may be achieved by surface modification.

\section{INTRODUCTION}

Removal of leukocytes from blood before transfusion is considered to be important for various reasons. It is well known that the transfusion of leukocyte-containing blood components may induce alloimmunization against these cells, which cause immune reactions after repeated transfusions. ${ }^{1,2}$ Nonhemolytic febrile transfusion reactions (NHFTR) are often accompanied by fever, headache, nausea, and diarrhea and may sometimes be fatal. Moreover, alloimmunization may result in refractoriness against platelet transfusions. ${ }^{3}$

*To whom correspondence should be addressed at University of Twente, Department of Chemical Technology, P.O. Box 217, 7500 AE Enschede, The Netherlands.

Journal of Biomedical Materials Research, Vol. 25, 1459-1480 (1991)

(C) 1991 John Wiley \& Sons, Inc.

CCC 0021-9304/91/121459-22\$4.00 
Several authors have reported that these effects may be prevented by the use of leukocyte poor blood components. ${ }^{4-7}$

Since 1974, it is known that renal allograft survival is decreased in patients who have not been transfused previously, or who have been transfused with leukocyte poor blood, as compared to patients transfused with red blood cell concentrates. ${ }^{8}$ Immunosuppressive effects, such as increased suppressor cell activity, are likely to account for this phenomenon. ${ }^{9}$ It has been speculated that leukocyte-contaminated blood components may also reduce the immune response to cancer cells and thereby facilitate the growth of metastases and the recurrence of tumors after surgery.,11 When adequate proof for this effect is obtained, it is attractive to postulate that transfusion of leukocyte depleted blood is potentially beneficial for patients undergoing surgery for tumors, such as colorectal carcinoma. ${ }^{12}$

In addition, various blood-borne viruses are predominantly associated to leukocytes and may be transmitted during blood transfusion. Removal of leukocytes from blood proved to be effective in reducing the transfer of cytomegalovirus $(\mathrm{CMV})^{13}$, human T-cell leukemia virus (HTLV-I), ${ }^{14}$ or human immunodeficiency virus (HIV). ${ }^{15}$

Techniques which have been used for the removal of leukocytes from blood cell preparations include differential centrifugation, sedimentation, filtration, washing, and successive freezing and thawing of blood. ${ }^{16-18}$ Although all these procedures have inherent advantages and limitations, filtration has become very popular because of its simplicity, clinical effectiveness, relatively low costs, and its use at the bedside. ${ }^{19-21}$

Removal of leukocytes from blood through filtration was already described in $1928,{ }^{22}$ but it took many years before a modification of this method led to its clinical use. ${ }^{23}$ Large-scale application of leukocyte filters started in the early 1970s, after the introduction of the first commercially available blood filter, which consisted of a column filled with tightly packed cotton wool fibers. ${ }^{24}$ Since that time, several modified blood filters have been developed and tested clinically. ${ }^{21,25-28}$ Although high filter efficacies have been obtained with fibers of different synthetic materials, or by improvement of the nonwoven filter structure and fiber diameter, further optimization of leukocyte filters is still needed. ${ }^{29}$

Thus far, the optimization of filter materials is achieved rather empirically. The development of new filter materials would be served by a better understanding of the mechanisms causing depletion of leukocytes by the filter. Very little is known about these mechanisms so far. It has been suggested that leukocyte filtration is governed by both sieving and adhesion, ${ }^{16,30}$ but the quantitative contribution of each factor is still unclear. ${ }^{18}$

To study the mechanisms of leukocyte filtration, the effects of mechanical sieving and cell adhesion during leukocyte filtration should be included. With regard to the mechanical aspects of leukocyte filtration, it has been reported that, due to differences in cellular deformability, most leukocytes will plug passages smaller than $5 \mu \mathrm{m}$, whereas erythrocytes will easily pass pores larger than $3 \mu \mathrm{m} .{ }^{31-37}$ However, these studies employed either flow through small capillaries or flow through Nuclepore membranes, which may be re- 
garded as screen filters with a narrow size distribution of tubular pores. Leukocyte filters, which are usually classified as depth filters, have distinct flow characteristics, which depend on the shape and the distribution of the pores. Moreover, the mechanisms of depth filtration and screen filtration differ significantly. ${ }^{38}$ Consequently, the results obtained from rheological studies, cannot simply be applied to leukocyte filter optimization.

The aim of the study presented here is to investigate the contribution of the filter structure to the depletion of leukocytes. We have prepared several model filters by stacking microporous polyurethane membranes with varying pore size distributions. In this way, the pore size distribution can be adjusted throughout the filter. In order to investigate the usefulness in routine blood filtration, the effectiveness of our model filters was compared with several commercially available nonwoven leukocyte filters.

\section{MATERIALS AND METHODS}

\section{Filter materials}

Polyurethane membrane filters were prepared from medical grade Pellethane 2363-80A (Dow Chemical Nederland BV, Delfzijl, the Netherlands). Polyurethane was first extruded at $190-220^{\circ} \mathrm{C}$ to improve its solubility in organic solvents. In order to purify the polymer, a $10 \%$ solution of polyurethane in dimethylformamide was slowly added to a 10 -fold excess of water which was stirred at high speed. The precipitate was collected by filtration, and dried in vacuo at $60^{\circ} \mathrm{C}$.

Polyester nonwoven filter materials, used for the manufacturing of commercially available Cellselect ${ }^{\circledR}$ leukocyte filters, were obtained from the manufacturer (NPBI, Emmer-Compascuum, The Netherlands). Three different materials, i.e., a prefilter, a coarse main filter and a fine main filter, varying in thickness, fiber size, and porous structure, were used.

\section{Membrane preparation}

Series of polyurethane (PU) membranes were prepared by two different salt suspension techniques. Both techniques were slightly modified compared with methods reported in the literature. ${ }^{39-44}$ For instance, an alternative solvent system was used here. Table I gives a survey of the different conditions used to prepare the membranes.

Membrane types $7.3,7.4$, and 7.5 were prepared from solutions of PU in dimethylformamide $(7 \mathrm{w} / \mathrm{v}-\%)$ in which particles of sodium citrate (Janssen, Beerse, Belgium) with size distributions of 38-63 $\mu \mathrm{m}, 63-106 \mu \mathrm{m}$, and 106$212 \mu \mathrm{m}$, respectively, were suspended. Particles with these distributions were obtained by sieving. For the respective membranes, the concentration of particles used was 88,89 , and $90 \mathrm{v} / \mathrm{v} \%$ with respect to PU. After degassing, thin films $(500 \mu \mathrm{m})$ were cast from these suspensions on clean glass plates, after which the PU was coagulated by immersing the plates in ethanol for $12 \mathrm{~min}$. 


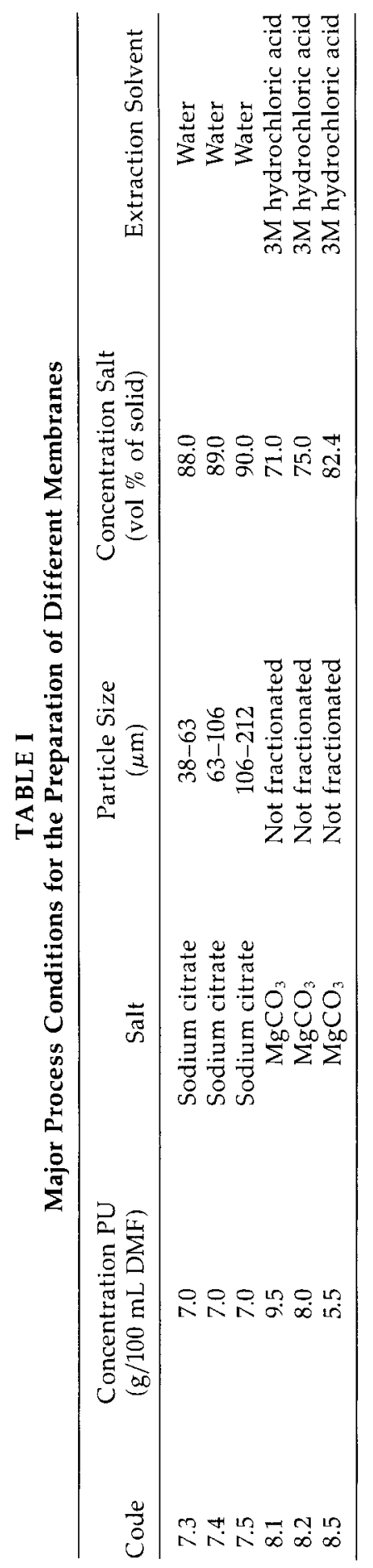


The salt particles were finally washed out with water. This resulted in microporous membranes with a pore size distribution, mainly dependent on the size of the salt particles used.

Filter types 8.1,8.2, and 8.5 were prepared from solutions of 9.5, 8.0, and $5.5 \mathrm{w} / \mathrm{v} \%$ PU respectively in dimethylformamide in which particles of magnesium carbonate (Janssen, Beerse, Belgium) $\left(\mathrm{MgCO}_{3}\right)$ were suspended. These particles were not fractionated before use. Salt particles were added in amounts of 71,75 , and $82.4 \mathrm{v} / \mathrm{v} \%$, respectively, with respect to PU. The suspensions were treated ultrasonically for at least 1 day to break down particle aggregates. The size of the remaining particles was found to be less than $1 \mu \mathrm{m}$, as measured by scanning electron microscopy (SEM). Films of these suspensions were prepared and coagulated as described above. Thereafter, the salt particles were dissolved by extraction with $3 \mathrm{M}$ hydrochloric acid. It turned out that the amount of PU, dissolved in the casting suspension, was directly correlated to the pore size distribution in the resulting membranes.

After preparation, all membranes were washed with distilled water for at least 1 day, rinsed in ethanol, and finally dried in air. Membranes were kept in the dark at room temperature.

\section{Filter preparation}

Filters were prepared by stacking membranes described in the membrane preparation section. First, thin layers with a thickness of $1.0 \mathrm{~mm}$ were cut from a stack of three to five membranes. Three of these layers, with a total thickness of $3 \mathrm{~mm}$, were then mounted together in a special polycarbonate filter housing (Schleicher \& Schüll, type FP 050/0). Two of these filter units were finally connected by a small polyvinylchloride tube, to achieve sufficient depth filter capacity.

In this way, both symmetric and asymmetric filters were prepared. Symmetric filters, with a total thickness of $6.0 \mathrm{~mm}$, are composed of identical membranes, and have a uniform pore size distribution throughout the filter. Asymmetric filters are composed of a stack of different membranes, with a total thickness of $6.0 \mathrm{~mm}$, in such a way that the average pore size decreases in the direction of blood flow through the filter. These filters contained six layers of $1.0 \mathrm{~mm}$ thickness, each composed of identical membranes, type $7.5,7.4,8.5,7.3,8.2$, and 8.1 respectively.

Nonwoven filters were prepared in a similar way. Thus, symmetric nonwoven filters were composed of a stack $6.0 \mathrm{~mm}$ of identical filter layers. Asymmetric nonwoven filters contained three layers of $2.0 \mathrm{~mm}$ thickness, each composed of identical filter layers, prefilter, coarse filter, and fine filter, respectively.

\section{Characterization of filter materials}

Surfaces and cross sections of each membrane were examined by SEM. Pore size distributions were determined in duplo by counting 200-300 open 
passages observed in pictures of representative structures on both sides of the membrane, using a particle size analyzer. It is generally assumed that pores are Gaussian distributed, so that their distribution may be characterized by an average pore size and a standard deviation.

The overall average pore size of the membrane was determined by porometry. Membranes were soaked with a special inert solvent to fill all pores. A Coulter porometer was used to measure the pressure increase which is needed to remove the fluid from the sample. With the porometer the average pore size can be automatically calculated from the pressure curve. All measurements were carried out in duplo.

Cut-off values of the membranes were determined in duplo by filtration with glass beads. Depending on the pore size distribution of the membrane, either $10-70 \mu \mathrm{m}$ spheres or $0-20 \mu \mathrm{m}$ spheres were used. An amount of glass beads, matching about one monolayer on top of the membrane, was filtered with $100 \mathrm{~mL}$ of distilled water. Size distribution of glass beads in the filtrate were determined by counting particles observed on SEM micrographs. The arbitrarily chosen cut-off particle size means, that at least $98 \%$ of the particles in the filtrate are smaller.

The porosity, or pore volume fraction, of the membranes was determined in duplo from the weight and volume of dry samples. Sample volumes were calculated from the filter thickness, as averaged from five measurements (SEM). For calculating the porosity, the density of air was neglected compared to the density of the filter material, $1.13 \mathrm{~g} / \mathrm{mL}$ for polyurethane, according to the manufacturer.

The characterization of nonwovens was carried out in a similar way as the characterization of membranes, as described above. A density of $1.38 \mathrm{~g} / \mathrm{mL}$ for polyester fibers, according to the manufacturer, was taken to calculate the porosity of these materials.

\section{Blood cells}

Blood from healthy human donors was collected in blood bags containing citrate-phosphate-dextrose-adenine (CPDA). After storage for $10-15 \mathrm{~h}$ at $20^{\circ} \mathrm{C}$, the bags were centrifuged for $10 \mathrm{~min}\left(3600 \mathrm{~g}\right.$ at $\left.20^{\circ} \mathrm{C}\right)$ to remove the plasma layer from the packed cell suspension. Filtration experiments were performed, within $16 \mathrm{~h}$ after blood collection, with pooled units of the packed cells, diluted with an aqueous solution containing $0.9 \%$ sodium chloride (saline) to a hematocrit of $60 \%$.

\section{Filtration procedure}

In a typical filtration experiment, filters were first rinsed with $200 \mathrm{~mL}$ of saline to remove air and to wet the filter surface. By varying the hydrostatic pressure over the filter, the initial saline flow was adjusted to $1.0 \mathrm{~mL} / \mathrm{s} \mathrm{in} \mathrm{ev-}$ ery new experiment. Blood filtration was started by connecting the blood cell 
reservoir to the filter. The hydrostatic pressure was kept constant throughout the entire filtration.

During filtration, samples of $5-10 \mathrm{~mL}$ of the filtrate were collected at different times, and analyzed for cell composition and concentration.

\section{Analysis of filtrate}

The total leukocyte count in filtrate samples was determined with an electronic particle counting technique. Aliquots of $20 \mu \mathrm{L}$ were diluted with $10 \mathrm{~mL}$ electrolyte containing solution. Lysis was induced with two drops of a saponin containing electrolyte solution. Remaining particles were then counted in $0.5 \mathrm{~mL}$ lysate sample, using a Coulter counter, with a $100-\mu \mathrm{m}$ counting tube opening. Measurements were carried out in duplo.

The first part of the filtrate was usually diluted by saline, present in the prerinsed filter. To account for this dilution, in all lysates, used in the counting, an additional spectrophotometric hemoglobin determination was performed. The adsorbance was measured at $370,415,500$, and $577 \mathrm{~nm}$. The hematocrit was measured according to a standard procedure. Samples of the filtrate were centrifuged at $3600 \mathrm{~g}$ for $10 \mathrm{~min}$. The free hemoglobin in the supernatant, was determined spectrophotometrically, as described above.

Concentrations of granulocytes, monocytes and T-lymphocytes were determined in selected samples with a standard direct binding assay for leukocyte subpopulations (DBA), which has been described in detail elsewhere. ${ }^{45}$ This assay uses ${ }^{125}$ I-labeled antibodies directed against specific structures on the membranes of different cell types.

\section{Analysis of the filter materials after filtration}

After leukocyte filtration some membrane filters were used for further evaluation. Small parts, about $1 \mathrm{~cm}^{2}$, were cut from the filter and fixed with formaldehyde containing solution, as described elsewhere. ${ }^{46}$ Fixed samples were embedded in methacrylate resin, according to standard procedures. Sections of $7 \mu \mathrm{m}$ were cut with a microtome. After staining with hematoxylin solution, the preparates were studied with a light microscope.

\section{RESULTS}

\section{Characterization of filter materials}

SEM micrographs of membranes (Fig. 1) demonstrate that, using the salt suspension technique, a series of membranes with different pore size distributions can be prepared. All membranes show an open and cellular pore structure, with a relatively narrow pore size distribution. Although some structural differences exist between the top and the bottom of membranes, 

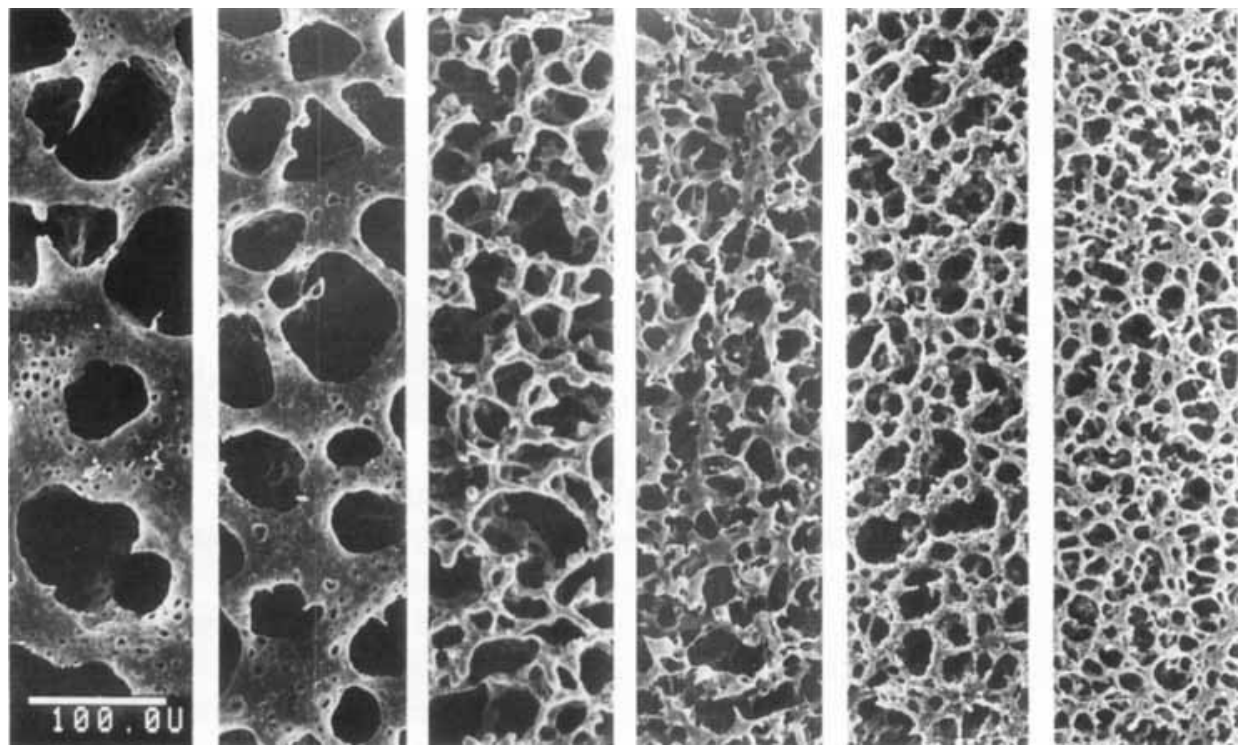

Figure 1. SEM micrographs of layers of the asymmetrical membrane filter. From left to right, the micrographs show membrane type 7.5 (top side), type 7.4 , type 8.5 , type 7.3 , type 8.2 , and type 8.1 (bottom side).

the pore size data (Table II) indicate that each single membrane has an almost symmetrical structure. Pore sizes determined with the Coulter porometer, which represent the average values throughout the membranes, are in reasonable agreement with the average pore sizes measured at the membrane surfaces, according to SEM. It also appears from Table II that the specific filter surfaces of the membranes, as calculated from a simple morphological model, adopted from literature, ${ }^{47}$ differ largely. This results directly from variations in pore sizes, as the porosity of the membranes is roughly comparable.

SEM micrographs of commercial nonwoven filter materials (Fig. 2) show the large structural differences of these materials as compared to the membrane structures from Figure 1. Nonwoven filters have an irregular and roughly shaped porous structure, with a relatively broad distribution of pore sizes (Table III). Although large structural differences exist between membrane filters, the specific filter surface of various nonwoven filters is comparable to the specific filter surface of membrane filters.

Using the pore size data from Tables II and III, asymmetric filter compositions may be illustrated schematically by their pore size distributions throughout the filter as shown in Figures 3 and 4 . These figures represent an idealized pore size distribution with a continuous decrease in pore size, while in practice there is a stepwise decrease of pore sizes throughout the filter.

\section{Blood filtration}

Both flow and leukocyte concentrations in the filtrate were measured as a function of time for each filter. From these measurements, differential leuko- 


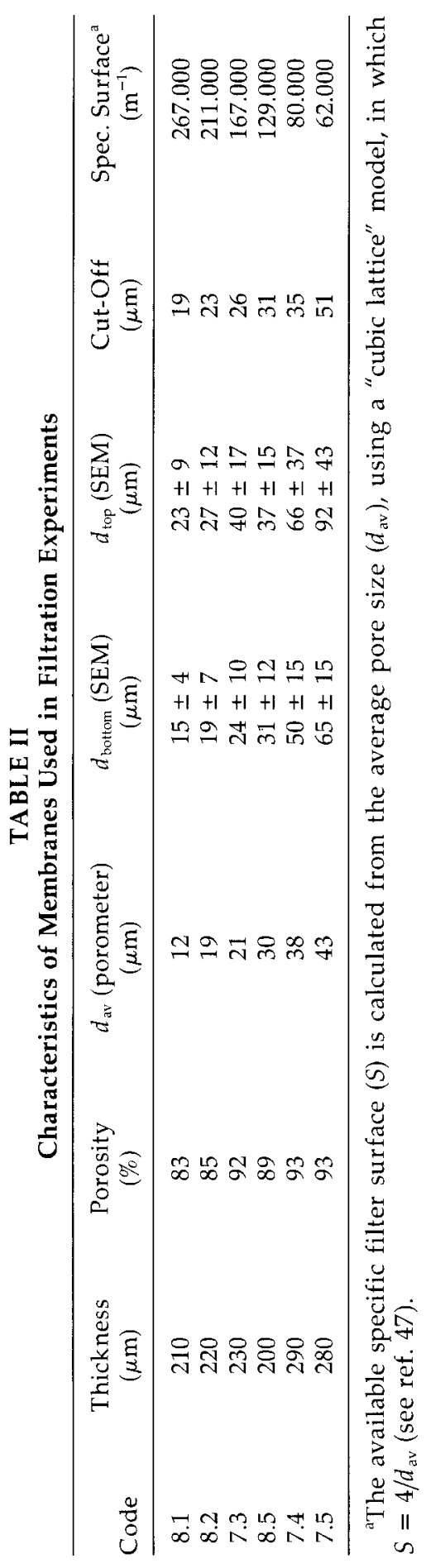



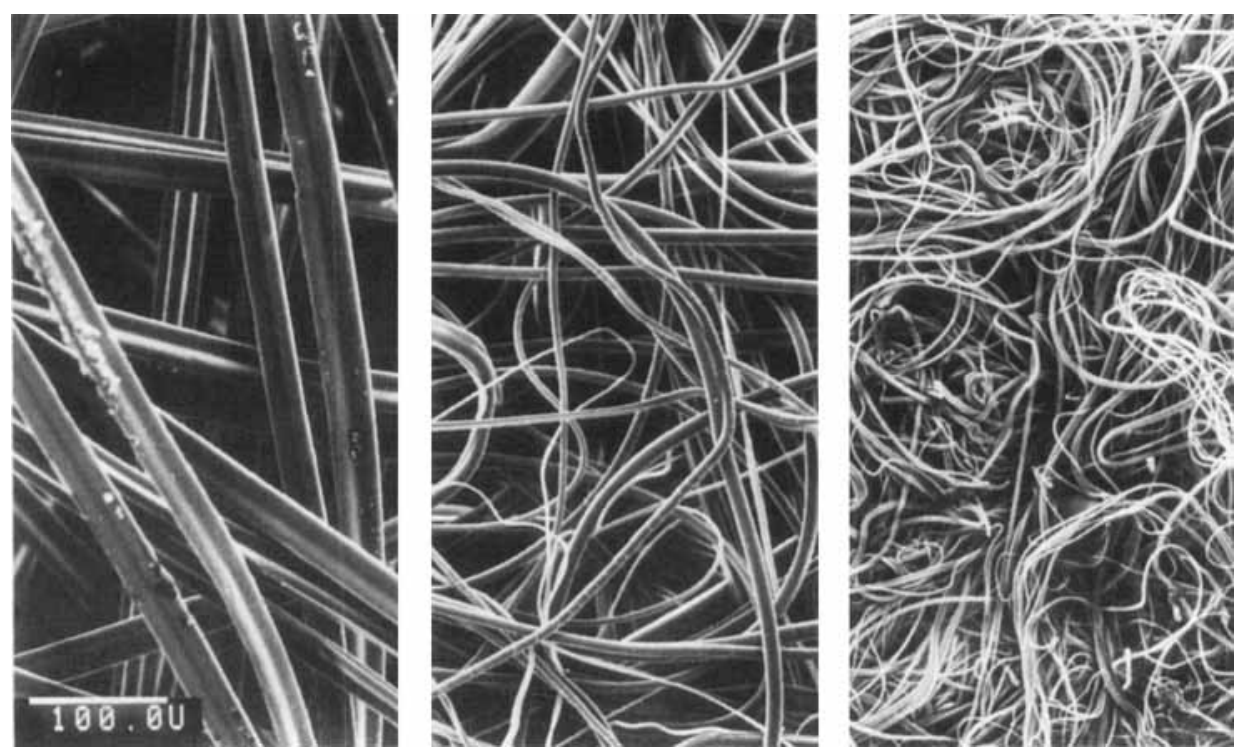

Figure 2. SEM micrographs of the layers of the asymmetrical nonwoven filter. From left to right, the micrographs show a prefilter layer (top side), a coarse main filter and a fine main filter (bottom side).

cyte retention and total leukocyte uptake by the filters were calculated. Figures $5(\mathrm{I})$ and $6(\mathrm{I})$ show the fraction of leukocytes which passed through the filters as a function of filtration time. A high leukocyte removal was obtained for relatively small pore size filters. These latter filters also gave rise to a fast drop of the initial flow [Figs. 5(II) and 6(II)]. From the removed fraction of leukocytes and the flow through the filter, the leukocyte uptake can be calculated. Figures 5(III) and 6(III) show the results. Figures 5(IV) and 6(IV) are obtained by time integration of the data from Figures 5(III) and 6(III). These figures show that filters with small pores do not have the largest leukocyte uptake capacity, although they remove these cells most efficiently. Filters with large pores do also have a small uptake capacity. The data in Figures 5(IV) and 6(IV) demonstrate that asymmetric filters are most efficient in the uptake of leukocytes.

The occurrence of hemolysis, caused by filtration of blood through membrane filters, was measured in samples taken after filtration of approximately $50 \mathrm{~mL}$ of blood (Table IV). Filtration through filters with small pores was accompanied by an increased hemoglobin level in filtrate samples. The hematocrit did not change significantly at higher rates of red cell destruction.

\section{Composition of the filtrate}

Because of differences in size, concentration and functions, ${ }^{48}$ various leukocyte populations may behave differently during filtration. Therefore, concentrations of granulocytes, lymphocytes and monocytes were measured in a selected number of filtrates, derived from blood. Both an asymmetric type 


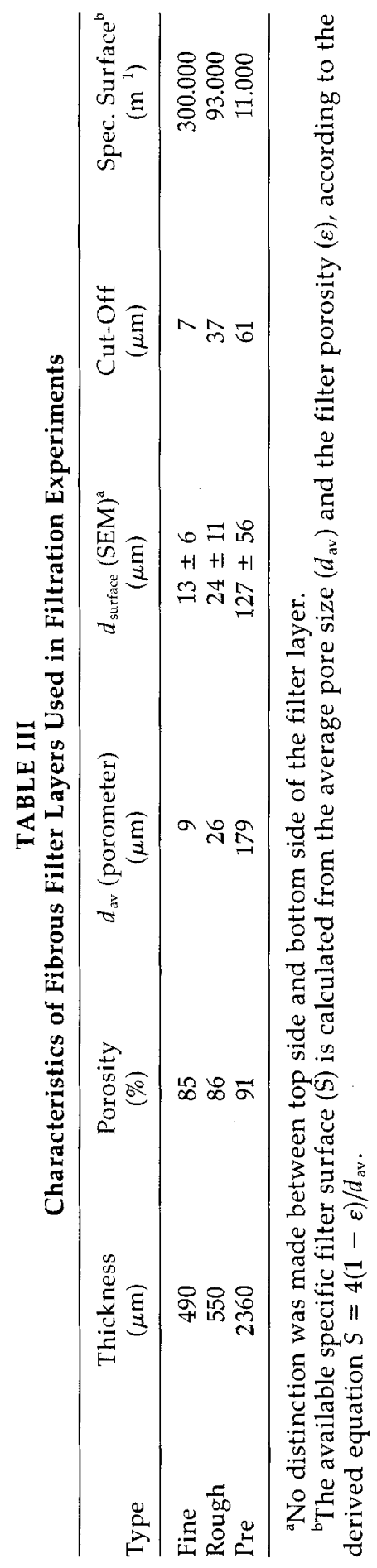




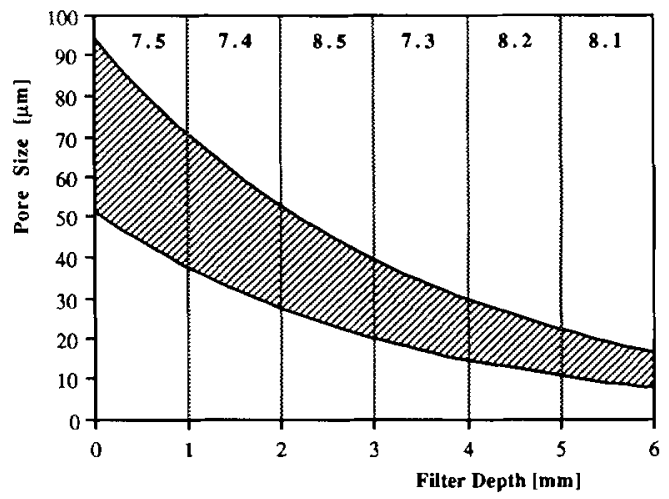

Figure 3. Idealized scheme of the pore size gradient in the asymmetrical membrane filter. The marked area represents the distribution of pore sizes as a function of filter depth.

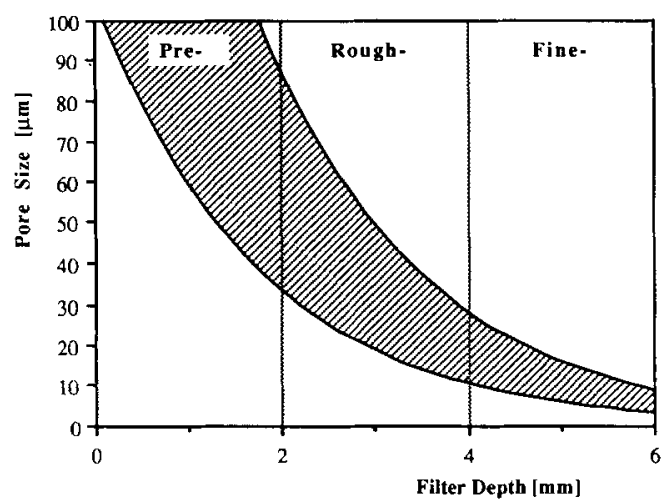

Figure 4. Idealized scheme of the pore size gradient in the asymmetrical nonwoven filter. The marked area represents the distribution of pore sizes as a function of filter depth.

filter and a symmetric type filter, composed of type 7.3 membranes, were used for this study.

Figure 7 shows the fractions of leukocyte populations which passed the filters as a function of filtration time. Both filters showed large differences between the different kinds of leukocyte populations. Lymphocytes passed relatively easily through both filters, whereas monocytes, and to a less extent also granulocytes, were well retained by the filters. For each type of leukocyte, the asymmetric filter shows superior removal as compared with the symmetric filter.

\section{Histological analysis of the filter after blood filtration}

Typical pictures of stained cross sections of the top section, the intermediate section, and the bottom section of an asymmetric filter and a sym- 


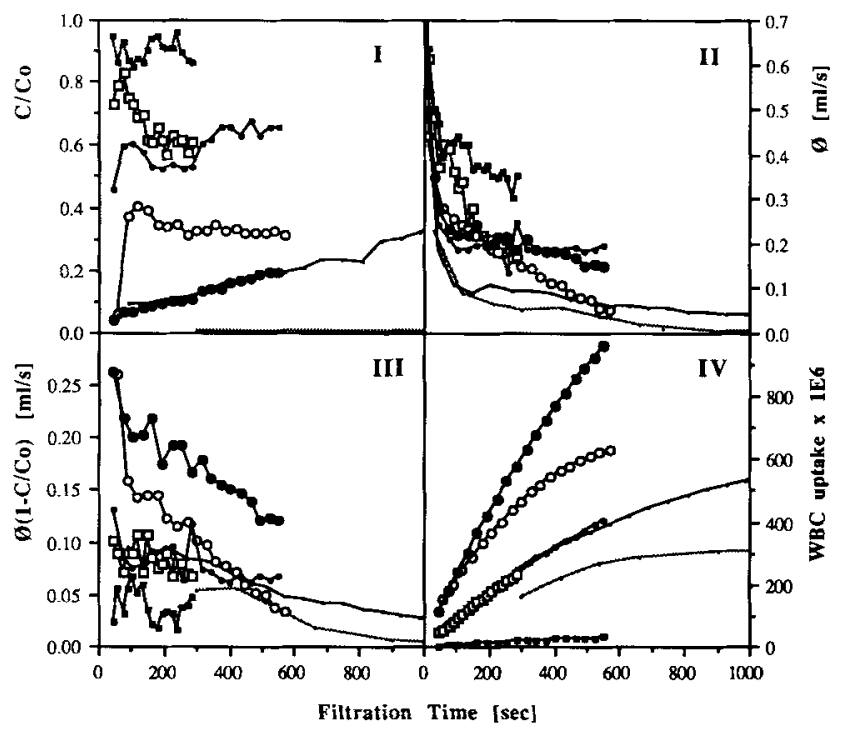

Figure 5. Filtration characteristics of membrane filters; filter $8.1(\sim)$, filter $8.2(-)$, filter $7.3(-\circ)$, filter $8.5(-\bullet)$, filter $7.4(-\square)$, filter 7.5 $(--)$, and an asymmetrical filter (- - ). Plots in the graphs show relative output of leukocytes (I), flux (II), differential leukocyte uptake by the filter (III), and total leukocyte uptake by the filter (IV) as a function of filtration time.

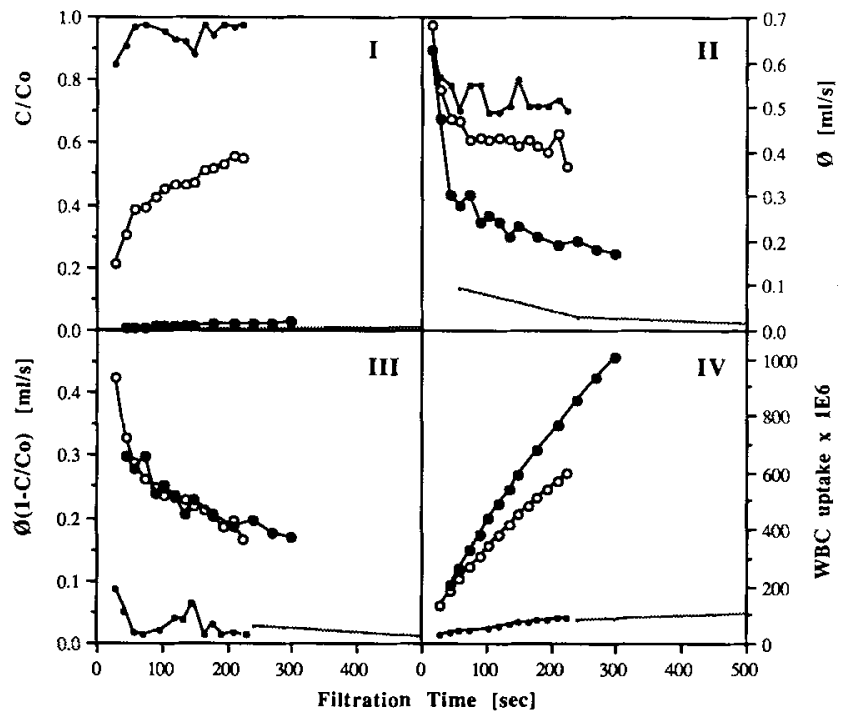

Figure 6. Filtration characteristics of fibrous filters; fine filter $(\sim)$, rough filter $(\longrightarrow)$, prefilter $(\longrightarrow)$, and an asymmetrical filter $(-\bullet)$. Plots in the graph show relative output of leukocytes (I), flux (II), differential leukocyte uptake by the filter III), and total leukocyte uptake by the filter IV as a function of filtration time. 
TABLE IV

Hemolysis after Filtration of $50 \mathrm{~mL}$ Blood

\begin{tabular}{lrc}
\hline Filtration & $\begin{array}{c}\text { Free Hemoglobin } \\
(\mathrm{mg} / \mathrm{L})\end{array}$ & $\begin{array}{c}\text { Hematocrit } \\
(\%)\end{array}$ \\
\hline Not filtered & 407 & 61 \\
8.1 & $>10000$ & 61 \\
8.2 & 1126 & 60 \\
7.3 & 1094 & 60 \\
8.5 & 1071 & 59 \\
7.4 & 757 & 62 \\
7.5 & 571 & 61 \\
Asym. & 2200 & 60 \\
\hline
\end{tabular}

metric filter are shown in Figure 8. Large amounts of platelets, most of them aggregated, were retained at the top sections of both filters [Figure 8(Ia) and 8(IIa)]. Within these aggregates, a considerable number of leukocytes, mainly granulocytes, were trapped. In the intermediate sections of the filters however, most of the blood cells are erythrocytes, as can be seen from Figures $8(\mathrm{Ib})$ and $8(\mathrm{IIb})$. These sections contain only a small number of leukocytes. Most distinct differences between both filters are found in the bottom sections. The bottom section of the symmetric filter [Fig. 8(Ic)] is almost ineffective in the removal of leukocytes. In contrast, the bottom section of the asymmetric filter, with much smaller pores compared to the symmetric filter section, significantly contributes to the retention of leukocytes. Figure 8(IIc) shows that large numbers of mainly lymphocytes are captured in the pores of this section.

\section{DISCUSSION}

In order to study the influence of pore size distributions on the efficiency of leukocyte filtration, the use of well defined model filters is a prerequisite. Conventional filter structures, composed of packed fibers, have a broad pore

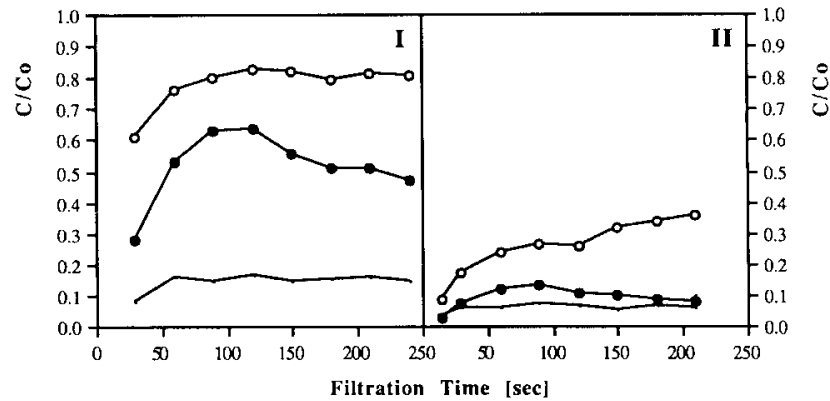

Figure 7. Filtration characteristics for different leukocyte subpopulations; monocytes ( -$)$, granulocytes $(-\longrightarrow)$, and lymphocytes $(-\infty-)$, after filtration through a symmetrical membrane filter type 7.3 (I) and after filtration through an asymmetrical membrane filter (II). 

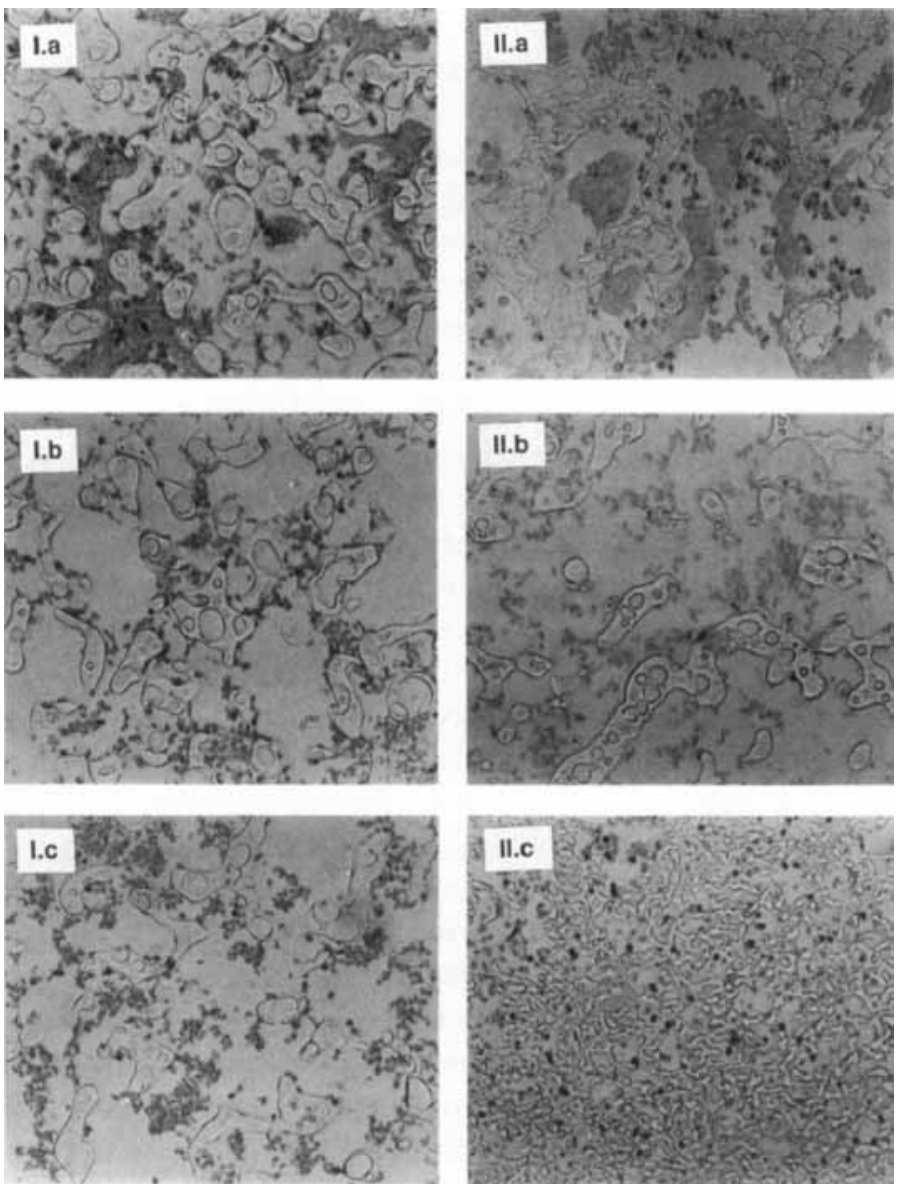

Figure 8. Stained cross sections of membrane filters after filtration of blood. Cross sections of a symmetric filter (I), and those of an asymmetric filter (II). In each series, from top to bottom, are shown top side (A), mediate section (B), and bottom section $(C)$, respectively (magnification $\times 250$ ).

size distribution, which is poorly defined. In contrast to nonwovens, membranes are composed of a continuous porous matrix, usually with a well defined structure. Most of the techniques to prepare membranes offer unique possibilities to adjust the pore structure. Open cellular structures, with a narrow pore size distribution may be obtained. A purpose of this study was to optimize the porous structure of leukocyte filters, with respect to their filtration efficiency, for which membrane structures offer several advantages.

A range of membranes, differing in pore size, were prepared by the use of salt suspension techniques. These membranes and fibrous material used in commercially available leukocyte filters showed a number of structural differences. Membrane structures are very regular, which is demonstrated by the relatively narrow pore size distributions according to SEM measurements. In contrast to these membrane structures, it is impossible to define an absolute pore size in the fibrous structures. In particular the apparent pore size of nonwovens will be largely dependent on the characterization method 
used. This is illustrated by the results presented in Table III, which show relatively large differences between cut-off values and average pore sizes as determined with SEM and porometry.

The results of membrane filtration experiments demonstrate that with filter type 8.1, with a pore size ranging from 11 to $19 \mu \mathrm{m}$, it is possible to remove almost all leukocytes from whole blood. However, clogging in an early stage rapidly stops the blood flow through this filter, thus causing a low uptake capacity. Another disadvantage of this filter is the high rate of hemolysis (Table IV), caused by a high shear stress exerted on the blood cells during filtration. It can thus be concluded that this small pore filter was not very suitable for leukocyte removal from blood. When larger pore size filters are applied, for instance filter type 7.5 with a pore size about $50-80 \mu \mathrm{m}$, the degree of hemolysis decreases significantly. However, these larger pore filters are also inefficient when the leukocyte uptake capacity is considered. This is caused by a relatively large leakage of leukocytes through the filter. However, blood flow is not impaired during the filtration.

With respect to filtration efficiency, asymmetric filters will have advantages over symmetric filters. Early stage clogging may be prevented by the partial removal of particles at the top section of the filter which contains layers with relatively large pores, whereas most of the remaining particles will be removed at the bottom section, containing layers with small pores. ${ }^{49}$ The results of our experiment (Fig. 5) show both a moderate leukocyte removal and a modest blood flow impairment for the asymmetric filter type. Both properties contribute to an optimal leukocyte uptake during filtration of blood. The same appears applicable for fibrous filters. For the study of the filtration properties of these filters, asymmetric structures have been rather arbitrarily chosen. It may be expected that the efficiency of asymmetric filters can be further improved by optimization of the pore gradient structure in the filters.

It appears that our membrane filters show a low capacity to remove leukocytes from blood, as compared to the nonwoven filters tested. Although SEM pictures of fibrous filter layers suggest a less efficient porous structure of the nonwoven filter, the asymmetric nonwoven filter removed almost twice as many leukocytes as the asymmetric membrane filter. This result may be attributed to a more efficient asymmetric structure of the nonwoven filter, as may be deduced from Figure 4 . It is also very likely that the filter material plays an important role in the retention of leukocytes. It is well known from literature that the adherence of leukocytes to polymer surfaces is largely dependent on the surface free energy of the material. ${ }^{50,51}$ In general, cell adhesion increases when the polymer surface is more hydrophilic. ${ }^{52-54}$ In this regard, polyurethane (PU) from the membranes or polyester (PET) from the fibers may behave differently towards leukocytes. As PET has a higher surface free energy than PU, the former are expected to retain more leukocytes, which is in agreement with our results.

The results of a histological study of the cell content of the membrane filters after filtration also demonstrate the contribution of leukocyte adherence in the filtration process. Leukocytes were found to stick to the filter surface 
and sometimes even spread, which suggests a very strong interaction with the filter material. In this respect, not only the smaller pores are capable to capture leukocytes, but the larger pores are susceptible to leukocytes as well. This explains the capacity of large pore filters to remove a small fraction of leukocytes. We observed that a large number of leukocytes was trapped by platelet aggregates, present in the top sections of the filter. Such interaction between platelets and leukocytes, which was also observed by Steneker in leukocyte filters for routine use ${ }_{r}^{46,55}$ may be explained in two ways. First, the adhesion and aggregation of platelets at the top section of the filter will locally reduce the apparent pore size. As smaller pores are more efficient in leukocyte retention compared to larger pores, leukocytes will easily be captured by the pores which are already partially clogged by platelets. Secondly, there is evidence that leukocyte adherence is promoted at surfaces covered with adherent platelets. ${ }^{56}$ This effect has been attributed to the release of adhesive proteins like fibrinogen, fibronectin, and von Willebrand factor by activated platelets.

After most of the platelets have been removed at the top section of the filters, the middle filter sections are hardly effective with regard to the removal of leukocytes. This is indeed demonstrated in Figures 8(IIa) and 8(IIb), which only show a few leukocytes in the middle filter section. The bottom section of the symmetric filters functions even worse. In contrast, the bottom section of the asymmetric filter is rather efficient in the removal of leukocytes, due to the much smaller pores of this section. As can be seen in Figure 8(IIc), mainly lymphocytes are captured by these pores. Whereas most of the granulocytes are most probably retained at the filter top sections, by means of adhesion to the filter material, most of the lymphocytes are probably removed by sieving through the small pores at the filter bottom section.

This important distinction between different leukocyte subpopulations is also demonstrated by cell analysis of filtered blood. Large differences were found between amounts of monocytes, granulocytes, and lymphocytes in the filtrate. This is not surprising, as leukocyte subpopulations may significantly differ in size. Granulocytes and monocytes may be captured easier by an arbitrary filter pore than lymphocytes, which are somewhat smaller in size. ${ }^{48}$ Moreover, lymphocytes are in general less reactive towards polymer surfaces, ${ }^{57-62}$ whereas monocytes will adhere very easily to foreign surfaces. ${ }^{60-65}$ It is generally known that lymphocytes are difficult to remove, compared to other leukocytes. ${ }^{66,67}$ This is also confirmed by our results.

\section{CONCLUSIONS}

Polyurethane membrane filters were prepared to study the influence of pore size distributions on the mechanisms involved in leukocyte filtration. From our experiments we conclude that the pore size distribution has a considerable effect on the filtration efficiency. Two cases have to be distinguished.

First, when significant adhesion of leukocytes occurs, such as the adhesion of granulocytes onto polyurethane filter surfaces, the filter efficiency may be 
improved by increasing the filter surface, available for leukocyte adhesion. In our approach, this can indirectly be achieved by decreasing the pore size. In addition, smaller pores may also promote the contact between leukocytes and filter material and thus enhance adhesion. However, small pore size filters induce excessive adhesion of leukocytes to pores at the top section of the filter, which leads to rapid clogging of the filter. Clogging may be avoided by applying a gradual decrease of the pore size in the direction of the blood flow. We demonstrated that these asymmetric leukocyte filters show optimal filtration characteristics.

Second, when adhesion of leukocytes is less pronounced, as in the case of lymphocytes onto polyurethane filter surfaces, increasing the filter surface is of no use. In this case the pore size may play a direct role because lymphocytes are captured by the sieving action of small pores. As asymmetric filter structure to avoid clogging may also be applied here.

Thus, in this study we have demonstrated that both adhesion and sieving mechanisms are involved in leukocyte filtration, although cell adhesion play a predominant role.

This work was supported by the 'Nederlands Produktie Laboratorium voor Bloedtransfusieapparatuur en Infusievloeistoffen BV' (NPBI), Emmer-Compascuum, The Netherlands.

We would like to thank Tineke Palfenier, Sonja Visser, and Marco Koppelman of the Central Laboratory of the Blood Transfusion Service of the Netherlands Red Cross (CLB), Amsterdam, The Netherlands, for their assistance in the analysis of filtrated blood.

\section{References}

1. T.E. Brittingham and H. Chaplin, Jr., "Febrile transfusion reactions caused by sensitivity to donor leukocytes and platelets," J. Am. Med. Ass., 165, 819-825 (1957).

2. R. Payne, "The association of febrile transfusion reactions with leukoagglutinins," Vox Sang., 2, 233-241 (1957).

3. J. G. Eernisse and A. Brand, "Prevention of platelet refractoriness due to HLA antibodies by administration of leukocyte-poor blood components," Exp. Hematol., 9, 77-83 (1982).

4. H. A. Perkins, R. Payne, J. Ferguson, and M. Wood. "Nonhaemolytic transfusion reactions. Quantitative effects of blood components with emphasis on isoantigenic incompatibility of leucoctes," Vox Sang., 11, $578-600(1966)$.

5. M.F. Murphy, P. Metcalfe, H. Thomas, J. Eve, J. Ord, T. A. Lister, and A.H. Waters, "Use of leukocyte-poor blood components and HLAmatched-platelet donors to prevent HLA alloimunization," $\mathrm{Br} . J$. Haemat., 62, 529-534 (1986).

6. G. Sirchia, P. Rebulla, L. Mascaretti, N. Greppi, C. Andreis, S. Rivolta, and A. Parravicini, "The clinical importance of leukocyte depletion in regular erythrocyte transfusions," Vox Sang., 51: suppl. 1, 2-8 (1986).

7. A. Brand, "White cell depletion, why and how?" in Transfusion Medicine in the 1990's, S. T. Nance (ed.), American Association of Blood Banks, Arlington, 1990.

8. G. Opelz and P.I. Terasaki, "Poor kidney-transplant survival in recipients with frozen-blood transfusions or no transfusions," Lancet, 2, 696-698 (1974). 
9. H.A. Perkins, "Transfusion-induced immunologic unresponsiveness," Trans. Med. Rev., 2, 196-203 (1988).

10. P.I. Tartter and D.M.A. Francis, "Blood transfusion and tumor growth," Transplant. Proc., 20, 1108-1111 (1988).

11. P.I. Tartter, B. Steinberg, D. M. Barron, and G. Martinelli, "Transfusion history, $\mathrm{T}$ cell subsets and natural killer cytoxicity in patients with colorectal cancer," Vox Sang., 56, 80-84 (1989).

12. W.G. van Aken, "Does perioperative blood transfusion promote tumor growth?," Trans. Med. Rev., 4, 243-252 (1989).

13. Y.C.E. de Graan-Hentzen, J.W. Gratama, G.C. Mudde, L.F. Verdonck, J. G. A. Houbiers, A. Brand, F. W. Sebens, A. M. van Loon, T. H. The, R. Willemze, and G.C. de Gast, "Prevention of primary cytomegalovirus infection in patients with hematologic malignancies by intensive white cell depletion of blood products," Transfusion, 29, 757760 (1989).

14. $\mathrm{K}$. Okochi and $\mathrm{H}$. Sato, "Transmission of adult $\mathrm{T}$-cell leukemia virus (HTLV-I) through blood transfusion and its prevention," AIDS Res., 2: suppl. 1, 157-161 (1986).

15. S. M. Bruisten, M. Tersmette, M.R. Wester, A.H.V. Vos, M.H.G.M. Koppelman, and J. G. Huisman, "Efficiency of leukocyte filtration and a freezing/thawing procedure for removal of human immunodeficiency virus infected cells from blood," Transfusion, 30, 833-837 (1990).

16. B. Wenz, "Leukocyte-poor blood," CRC Crit. Rev. Clin. Lab. Sci. 24, 1-20 (1986).

17. J. G. Treleaven, M. R. C. Path, M. McGregor, and J. Blagdon, "An evaluation of some of the methods currently available for the production of leukocyte-poor blood," Clin. Lab. Haemat., 6, 45-49 (1984).

18. A.S. B. Hughes and B. Brozovic, "Leukocyte depleted blood: an appraisal of available techniques," Br. J. Haematol., 50, 381-386 (1982).

19. E. MacNamara, S. Clarke, and S. R. McCann, "Provision of leukocyte poor blood at the bedside," J. Clin. Pathol., 37, 669-672 (1984).

20. H. T. Meryman and M. Hornblower, "The preparation of red cells depleted of leukocytes-Review and evaluation," Transfusion, 26, 101106 (1986).

21. G. Sirchia, B. Wenz, P. Rebulla, A. Parravicini, V. Carnelli, and F. Bertolini, "Removal of white cells from red cells by transfusion through a new filter," Transfusion, 30, 30-33 (1990).

22. A. Fleming, "A simple method of removing leucocytes from blood," Br. J. Exp. Pathol., 7, 281-286 (1928).

23. T. J. Greenwalt, M. Gajewski, and J. L. McKenna, "A new method for preparing buffy coat-poor blood," Transfusion, 2, 221-229 (1962).

24. P. Diepenhorst, R. Sprokholt, and H. K. Prins, "Removal of leukocytes from whole blood and erythrocyte suspensions by filtration through cotton wool. I. Filtration technique," Vox Sang., 23, 308-320 (1972).

25. B. Lichtiger, L. del Valle, M. Armintor, and J. M. Trujillo, "Use of Imugard IG500 filters for preparation of leukocyte poor blood for cancer patients," Vox Sang., 46, 136-141 (1984).

26. E. L. Snyder, L. DePalma, and P. Napychank, "Use of polyester filters for the preparation of leukocyte-poor platelet concentrates," Vox Sang., 54, 21-23 (1988).

27. R. N. I. Pietersz, W. J.A. Dekker, and H.W. Reesink, "A new cellulose acetate filter to remove leukocytes from buffy-coat-poor red cell concentrates," Vox Sang., 56, 37-39 (1989).

28. T. S. Kickler, W. Bell, P. M. Ness, H. Drew, and D. Pall, "Depletion of white cells from platelet concentrates with a new adsorption filter," Transfusion, 29, 411-414 (1989)

29. F. J. Pikul, R. P. Farra, M. B. Boris, L. Estok, D. Marlo, M. Wildgen, and H. Chaplin, "Effectiveness of two synthetic fiber filters for removing white cells from AS-1 red cells," Transfusion, 29, 590-595 (1989). 
30. P. Diepenhorst, "Removal of leukocytes from whole blood and erythrocyte suspensions by filtration through cotton wool. VII. Studies on possible mechanisms." Thesis Delft University of Technology, The Netherlands, 1974.

31. M. A. Lichtman, "Rheology of leukocytes, leukocyte suspensions, and blood in leukemia," J. Clin. Invest., 52, 350-358 (1973).

32. M.A. Lichtman and E.A. Kearney, "The filterability of normal and leukemic human leukocytes," Blood Cells, 2, 491-506 (1976).

33. P. Gaehtgens, C. Dührssen, and K. H. Albrecht, "Motion, deformation, and interaction of blood cells and plasma during flow through Narrow capillary tubes," Blood Cells, 6, 799-812 (1980).

34. S. Chien, E. A. Schmalzer, M. M. L. Lee, T. Impelluso, and R. Skalak, "Role of white blood cells in filtration of blood cell suspensions," Biorheology, 20, 11-27 (1983).

35. R. Skalak, L. Soslowsky, E. Schmalzer, T. Impelluso, and S. Chien, "Theory of filtration of mixed blood suspensions," Biorheology, 24, 3552 (1987).

36. G. P. Downey and G. S. Worthen, "Neutrophil retention in model capillaries: deformability, geometry, and hydrodynamic forces," J. Appl. Physiol., 65, 1861-1871 (1988).

37. S. J. Gao and H. Niimi, "Blood cells filtration at low flow rate," in Blood Flow in Large Arteries: Applications to Artherogenesis and Clinical Medicine, D.W. Liepsch (ed.), Karger, Basel, 1990.

38. J.V. Fiore, W. P. Olson, and S. L. Holst, "Depth filtration," in Methods of Plasma Fractionation, J. M. Curling (ed.), Academic Press, London, 1980.

39. S. Gogolewski and A. J. Pennings, "Biodegradable materials of polylactides. 4a. Porous biomedical materials based on mixtures of polylactides and polyurethanes," Makromol. Chem., Rapid Commun., 3, 839845 (1982).

40. S. Murabayashi, H. Kambic, H. Harasaki, T. Morimoto, R. Yozu, and Y. Nose, "Fabrication and long-term implantation of semi-compliant small vascular porothesis," Trans. Am. Soc. Artif. Intern. Organs, 31, 5054 (1985).

41. P.T. Cahalan, C. M. Holmblad, and R.W. Pike, "Method for fabricating prosthesis material," US Patent Application 86/01095 (1986).

42. W. Lemm, "Verfahren zur Herstellung eines nicht toxischen Kunststoff-Schaum-Körpers," DE Patent 3.525.731 A1 (1987).

43. M. Okada, K. Sakai, H. Kimura, and Y. Ikada, "Synthetic vascular prosthesis and method for manufacturing same," EP Patent Application $0.271 .216(1988)$.

44. J. H. de Groot, A. J. Nijenhuis, P. Bruin, A. J. Pennings, R. P. H. Veth, J. Klompmaker, and H.W. B. Jansen, "Use of porous biodegradable polymer implants in meniscus reconstruction. I) Preparation of porous biodegradable polyurethanes for the reconstruction of meniscus lesions," Colloid Polym. Sci., 268, 1073-1081 (1990).

45. M.R. Wester, H.K. Prins, and J.G. Huisman, "The application of a novel radioimmunoassay for the detection of small amounts of leukocytes and platelets in red cell concentrates; implications for blood transfusion," Transfusion, 30, 117-125 (1990).

46. I. Steneker and J. Biewenga, "Histological and immunohistochemical studies on the preparation of leukocyte-poor red cell concentrates by filtration: the filtration process on cellulose acetate fibers," Vox Sang., 58, 192-198 (1990).

47. J. H. Aubert, "An objective characterization of the cell size of microcellular foams," J. Cell. Plast., 24, 132-145 (1988).

48. R.D. Dyson, "Specialized cells of the blood and lymph," in Cell Biology, a Molecular Approach, Allyn and Bacon, Boston, 1979. 
49. R. J. Akers, "Filtration pretreatment," in The Scientific Basis of Filtration, K. J. Ives (ed.), Noordhof International Publishing, Leyden, 1975, pp. 91-128.

50. D. R. Absolom, A.W. Neumann, W. Zingg, and J.G. van Oss, "Thermodynamic studies of cellular adhesion," Trans. Am. Soc. Intern. Organs, 25, 152-158 (1979).

51. A.W. Neumann, D.R. Absolom, C. J. van Oss, and W. Zingg, "Surface thermodynamics of leukocyte and platelet adhesion to polymer surfaces," Cell Biophys., 1, 79-92 (1979).

52. A.S.G. Curtis, J.V. Forrester, C. McInnes, and F. Lawrie, "Adhesion of cells to polystyrene surfaces," J. Cell Biol., 97, 1500-1506 (1983).

53. T. A. Horbett, J. J. Waldburger, B. D. Ratner, and A.S. Hoffman, "Cell adhesion to a series of hydrophilic-hydrophobic copolymers studied with a spinning disc apparatus," J. Biomed. Mater. Res., 22, 383-404 (1988).

54. D. Klee, W. Breuers, M. Bilo-Jung, C. Mittermayer, and H. Höcker, “Modifizierung von Polymeroberflächen zur Erhöhing der Zelladhesion," Angew. Makromol. Chem., 166/167, 176-189 (1989).

55. I. Steneker and J. Biewenga, "Histochemical and immunohistochemical studies on the preparation of white cell poor red cell concentrates: the filtration process using three different polyester filters," Transfusion, 31, 40-46 (1991).

56. D. J. Morley and I. A. Feuerstein, "Adhesion of polymorphonuclear leukocytes to protein coated and platelet adherent surfaces," Thromb. Haemost., 62, 1023-1028 (1989).

57. N. Yui, K. Sanui, N. Ogata, K. Kataoka, T. Okano, and Y. Sakurai, “Effect of crystallinity of polyamides on adhesion-separation behaviour of granulocytes," J. Biomed. Mater. Res., 17, 383-388 (1983).

58. N. Yui, K. Sanui, N. Ogata, K. Kataoka, T. Okano, and Y. Sakurai, "Reversibility of granulocyte adhesion using polyamine-grafted nylon-6 as a new column substrate for granulocyte separation," Biomaterials, 6, 409-415 (1985).

59. J.O. Lamvik, "Separation of lymphocytes from human blood," Acta Haemat., 35, 294-303 (1966).

60. R.R. MacGregor, P. J. Spagnuolo, and A.L. Lentvek, "Inhibition of granulocyte adherence by ethanol, prednisone, and asparin, measured with an assay system," N. Engl. J. Med., 291, 642-646 (1974).

61. D. R. Absolom, C. J. van Oss, and A.W. Neumann, "Elution of human granulocytes from nylon fibers by means of repulsive van der Waals forces," Transfusion, 21, 663-674 (1981).

62. G. Ghyka, I. Moldovan, and A. Calugaru, "Concanavalin-A increases the cell-adherence to plastic surfaces in leukocyte cultures," Rev. Roum. Biochem., 25, 333-340 (1988).

63. F. L. Rasp, C.C. Clawson, J.R. Hoidal, and J.E. Repine, "Quantitation and scanning electron microscopic comparison of human alveolar macrophage and polymorphonuclear leukocyte adherence to nylon fibers in vitro," J. Reticuloendothel. J., 25, 101-109 (1979).

64. J. J. Rinehart, B. J. Gormus, P. Lange, and M. E. Kaplan, "A new method for isolation of human monocytes," J. Immunol. Methods, 23, 207-212 (1978).

65. I. Dransfield, D. Corcoran, L. J. Partridge, N. Hogg, and D. R. Burton, "Comparison of human monocytes isolated by elutration and adherence suggests that heterogeneity may reflect a continuum of maturation/activation states, "Immunology, 63, 491-498 (1988).

66. J. Vakkila and G. Myllylä, "Amount and type of leukocytes in 'leukocyte-free' red cell and platelet concentrates," Vox Sang., 53, 76-82 (1987). 
67. B. Wenz, K. F. Gurtlinger, A. M. O'Toole, and E. P. Dugan, "Preparation of granulocyte-poor red blood cells by microaggregate filtration," Vox Sang., 39, 282-287 (1980).

Received March 2, 1991

Accepted June 3, 1991 